\title{
Study on the Removal of Thiosulfate from Wastewater by Catalytic Oxidation
}

\author{
Abdulaal Z. Al-Khazaal \\ Chemical Engineering and Materials \\ Engineering Department, Northern \\ Border University, Arar, Saudi Arabia \\ abdulaal.alkhazaal@nbu.edu.sa
}

\author{
Farooq Ahmad \\ Chemical Engineering and Materials \\ Engineering Department, Northern \\ Border University, Arar, Saudi Arabia \\ farooq.amin@nbu.edu.sa
}

\author{
Naveed Ahmad \\ Chemical Engineering and Materials \\ Engineering Department, Northern \\ Border University, Arar, Saudi Arabia \\ naveed.ahmad@nbu.edu.sa
}

\begin{abstract}
Wastewater streaming from industrial plants, including petroleum refineries, chemical plants, pulp and paper plants, mining operations, electroplating operations, and food processing plants, can contain offensive substances such as cyanide, sulfides, sulfites, thiosulfates, mercaptans and disulfides that tend to increase the chemical oxygen demand (COD) of the streams. In the present work, removal of thiosulfate from wastewater by catalytic oxidation using aluminum oxide as a catalyst was studied. Four main factors were considered, namely the initial thiosulfate concentration, the hydrogen peroxide concentrations, the amount of the catalyst and the operating temperatures. The analysis of thiosulfate and sulfate was carried out by using UV Visible Spectrophotometer. An empirical rate equation was developed.
\end{abstract}

Keywords-thiosulfate oxidation; kinetic model; catalytic oxidation; wastewater treatment

\section{INTRODUCTION}

Sulphur can be found in a variety of oxidation states, with three oxidation states of -2 (sulphide and reduced organic sulphur), 0 (elemental sulphur) and +6 (sulphate) being the most significant in nature. Thiosulfate is often produced from an incomplete oxidation of sulfides (pyrite oxidation) or partial reduction of sulfate. The reactions that lead to thiosulfate formation are [1]:

$$
\begin{aligned}
& 8 \mathrm{H}_{2} \mathrm{~S}+4 \mathrm{O}_{2} \rightarrow \mathrm{S}_{8}+8 \mathrm{H}_{2} \mathrm{O} \\
& \mathrm{H}_{2} \mathrm{~S}+3 / 2 \mathrm{O}_{2} \rightarrow 2 \mathrm{H}^{+}+\mathrm{SO}_{3}{ }^{2-} \\
& \mathrm{SO}_{3}{ }^{2-}+1 / 8 \mathrm{~S}_{8} \rightarrow \mathrm{S}_{2} \mathrm{O}_{3}{ }^{2-} \\
& \mathrm{H}_{2} \mathrm{~S}+2 \mathrm{O}_{2} \rightarrow 2 \mathrm{H}^{+}+\mathrm{SO}_{4}{ }^{2-} \\
& 2 \mathrm{~S}^{2-}+3 / 2 \mathrm{O}_{2} \rightarrow \mathrm{S}_{2} \mathrm{O}_{3}{ }^{2-} \\
& \mathrm{SO}_{4}+5 \mathrm{H}^{+} \rightarrow 1 / 2 \mathrm{~S}_{2} \mathrm{O}_{3}+5 / 2 \mathrm{H}_{2} \mathrm{O}
\end{aligned}
$$

Thiosulfates are stable in neutral or alkaline solutions, but not in acidic solutions, due to their decomposition to sulfite and sulfur, the sulfite being dehydrated to sulfur dioxide:

$$
\mathrm{S}_{2} \mathrm{O}_{3}{ }^{2-}(\mathrm{aq})+2 \mathrm{H}^{+}(\mathrm{aq}) \rightarrow \mathrm{SO}_{2}(\mathrm{~g})+\mathrm{S}(\mathrm{s})+\mathrm{H}_{2} \mathrm{O}
$$

This phenomenon could cause a rise of water $\mathrm{pH}$, increasing enrichment of $\mathrm{S}^{2-}$ and $\mathrm{S}^{0}$ in pore water, and finally plant death and inhibition of nitrification by sulfide toxicity, while the thiosulfates are a very aggressive species regarding metal corrosion. [2]

Based on [3], it was found that the concentration of thiosulfate in refinery wastewater is about $174 \mathrm{ppm}$ and for other wastewater, the thiosulfate concentration is about 2050ppm. According to [4], the traditional method of treating thiosulfate containing wastes is by oxidation to sulfate which can be accomplished either chemically by using oxidizing agents (e.g. peroxide) and oxidation catalysts (e.g. complexed copper (II)), or biological using aerobic processes such as activated sludge systems. Several aerobic and anaerobic microorganisms have the ability to utilize thiosulfate and other sulfur species as sources of energy. The most important aerobic microorganisms are sulfur chemolithoautotrophic bacteria (sulfur autotrophs), which use various reduced forms of sulfur as energy sources (electron donors) and oxygen as the electron acceptor. The final product of the complete dissimilatory oxidation of these compounds is sulfate. In [5], authors removed sulfide from wastewater by oxidizing it to sulfate using hydrogen peroxide in the presence of iron oxide catalyst. They synthesized iron oxide catalyst using the sol-gel technique and used different analytical techniques including scanning electron microscopy (SEM), Fourier transform infrared spectroscopy (FT-IR), thermal gravimetric analysis (TGA) and energy dispersive $\mathrm{x}$-ray spectroscopy (EDX). Their results were further explained by a kinetic study. Authors in [6] studied the treatment of wastewater containing thiosulfate by photo oxidation. They treated thiosulfate containing wastewater by aeration in the presence of UV light and found that the treatment process thus accelerates. They explained their results by carrying out a kinetic study of the process. Authors in [7] explored the treatment of sulfidic wastewater by aeration in the presence of ultrasonic vibration. They examined the oxidation of sulfide by aeration in the presence of ultrasonic vibration and found that the oxidation process was faster. Kinetics of the treatment process was also studied. Author in [8] studied the oxidation of thiosulfate in the presence of ultrasonic vibration. The process was studied at different initial thiosulfate concentrations, different ultrasonic vibrations and at different hydrogen peroxide dosages. The results were further explained by studying the kinetics of the treatment process.

Corresponding author: Abdulaal Z. Al-Khazaal 


\section{EXPERIMENTAL WORK}

\section{A. Materials}

Solutions with different thiosulfate concentrations were prepared synthetically. Sodium thiosulfate of $60 \%$ purity was used to prepare the test solutions. The changes in thiosulfate and sulfate concentrations were examined by the DR-5000 UVvisible spectrophotometer. Distilled water was used to prepare the test solution. The analysis of sulfate was carried out by DR$5000 \mathrm{UV}$-visible spectrophotometer using barium chloride as a reagent [5-8].

\section{B. Catalyst Preparation}

Aluminum oxide $\left(\mathrm{Al}_{2} \mathrm{O}_{3}\right)$ catalyst was prepared from aluminium chloride and ammonium hydroxide by the sol-gel technique. Aluminum oxide was used as a catalyst for the treatment of wastewater containing thiosulfate. The aluminum oxide prepared by the sol-gel technique was dried in the oven for $24 \mathrm{~h}$ before use [5].

\section{Methodology}

Oxidation of thiosulfate was carried out in a jacked glass reactor. The carried out experiments were divided into four groups. First the process was explored at different initial thiosulfate concentrations (700ppm, 1400ppm, 2100ppm and $2800 \mathrm{ppm}$ ). The second experiment was carried out at hydrogen peroxide loading $(0.8,1.6,2.4,3.2$ molar). In the third experiment, the treatment process was explored at different catalyst loadings $(0.25 \mathrm{~g}, 0.50 \mathrm{~g}, 1.0 \mathrm{~g}$ and $1.5 \mathrm{~g})$. Finally, the effect of temperature was explored. The process was repeated at $35^{\circ} \mathrm{C}, 45^{\circ} \mathrm{C}$, and $55^{\circ} \mathrm{C}$.

\section{RESULTS AND DISCUSSION}

\section{A. Effect of Initial Thiosulfate Concentration}

The process was carried out at four different initial thiosulfate concentrations. Catalyst and $\mathrm{H}_{2} \mathrm{O}_{2}$ amounts were kept constant throughout the experiments, $0.25 \mathrm{~g}$ and 0.8 molar respectively. The experiment was conducted at room temperature $\left(25^{\circ} \mathrm{C}\right)$. Figures 1 and 2 clarify that the rate of sulfate formation or/and thiosulfate drop increases as the initial concentration of thiosulfate increases. An increase in the initial thiosulfate concentration increases the amount of thiosulfate ions per sample to be reacted and form sulfate ions. Thus the formation of the sulfate ions increases. This finding shows that initial thiosulfate concentration is one of the main components in the rate law of this advanced oxidation process.

\section{B. Effect of Hydrogen Peroxide Concentration}

The treatment process was also explored at different hydrogen peroxide loadings. The results are shown graphically in Figures 3 and 4. We see that the concentration of sulfate formation and/or thiosulfate drop increases as the concentration of $\mathrm{H}_{2} \mathrm{O}_{2}$ increases from 0.8 to 1.6 molar. While, the formation of the sulfate ions is less as the $\mathrm{H}_{2} \mathrm{O}_{2}$ increases to 2.4 molar and 3.2 molar. These results showed that the optimum concentration for $\mathrm{H}_{2} \mathrm{O}_{2}$ in this experiment is 1.6 molar because most of thiosulfate ions were being consumed. The reason for this is that $\mathrm{H}_{2} \mathrm{O}_{2}$ mainly functions as the agent to produce hydroxyl radical that reacts in the thiosulfate oxidation process. Furthermore, the slope of the graph indicated the formation of sulfate ions which increases quickly at the first three readings for all $\mathrm{H}_{2} \mathrm{O}_{2}$ concentration and the slope starts to decline and become constant afterwards.

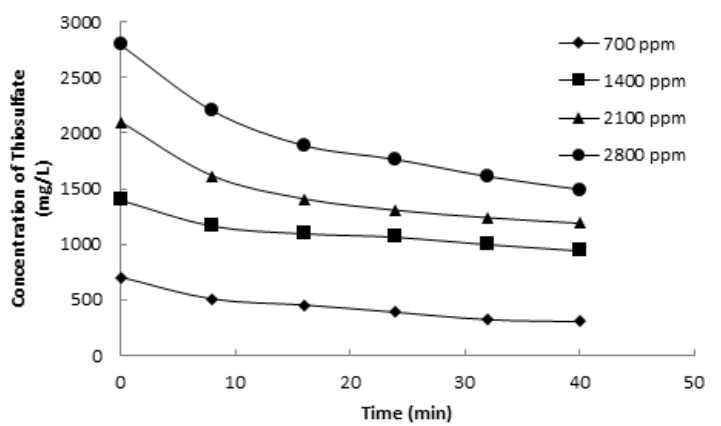

Fig. 1. Thiosulfate concentration versus time for different thiosulfate concentrations. Catalyst loading: $0.25 \mathrm{~g}, \mathrm{H}_{2} \mathrm{O}_{2}$ : $0.8 \mathrm{M}$.

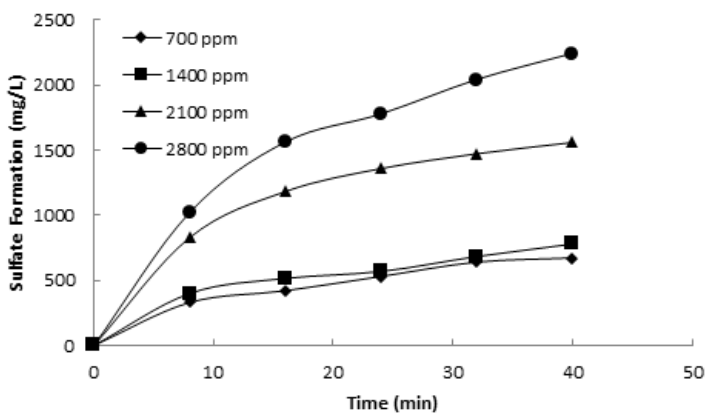

Fig. 2. Concentration of sulfate formation for different thiosulfate concentrations versus time. Catalyst loading: $0.25 \mathrm{~g}, \mathrm{H}_{2} \mathrm{O}_{2}: 0.8 \mathrm{M}$.

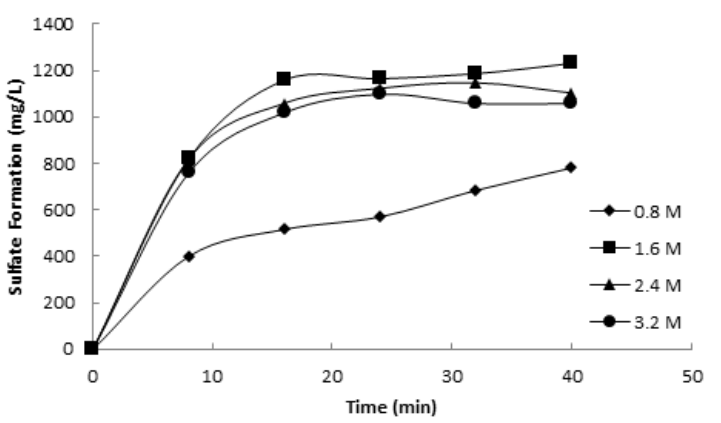

Fig. 3. Concentration of sulfate formation for different molar $\mathrm{H}_{2} \mathrm{O}_{2}$ concentrations versus time. Catalyst loading: $0.25 \mathrm{~g}$, initial thiosulfate concentration $=1400 \mathrm{ppm}$.

\section{Effect of Catalyst Loading}

The effect of catalyst loading was investigated. Figures 5 and 6 show different catalyst loadings ranging from 0.25 to $1.5 \mathrm{~g}$ used to explore the treatment process. The sulfate formation or/and thiosulfate drop were found to increase with increasing concentration of the catalyst, reaching the highest value of $1320 \mathrm{mg} / \mathrm{l}$ and $630 \mathrm{mg} / \mathrm{l}$ respectively, and then became constant. This may be due to the fact that when most of thiosulfate ions have reacted, the addition of higher quantities of catalyst would have no effect on the reaction. 


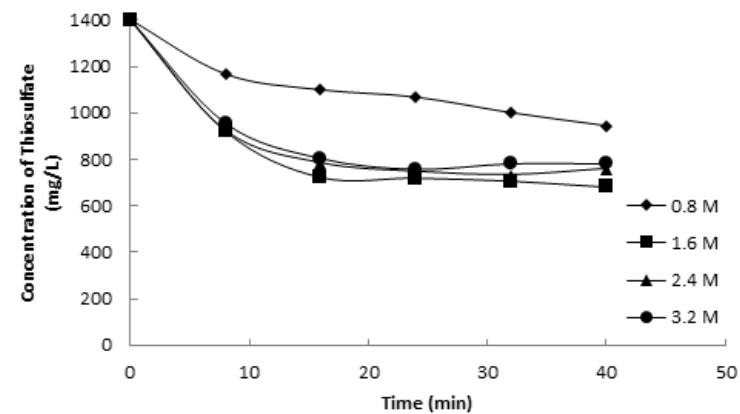

Fig. 4. Concentration of thiosulfate for different molar $\mathrm{H}_{2} \mathrm{O}_{2}$ concentrations versus time. Catalyst loading: $0.25 \mathrm{~g}$, initial thiosulfate concentration $=1400 \mathrm{ppm}$.

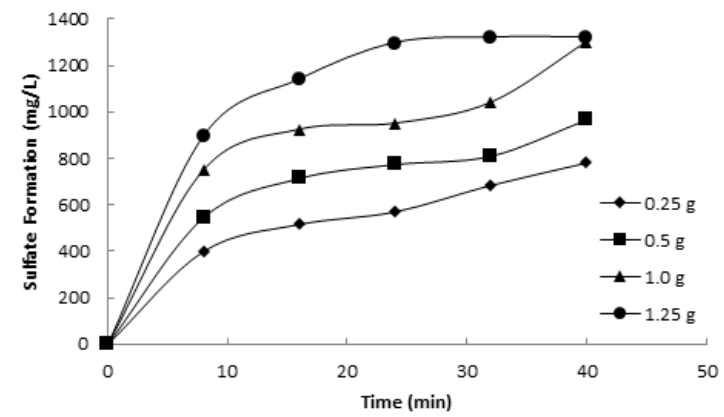

Fig. 5. Concentration of sulfate formation versus time for different catalyst amounts. $\mathrm{H}_{2} \mathrm{O}_{2}: 0.8 \mathrm{M}$, initial thiosulfate concentration=1400ppm.

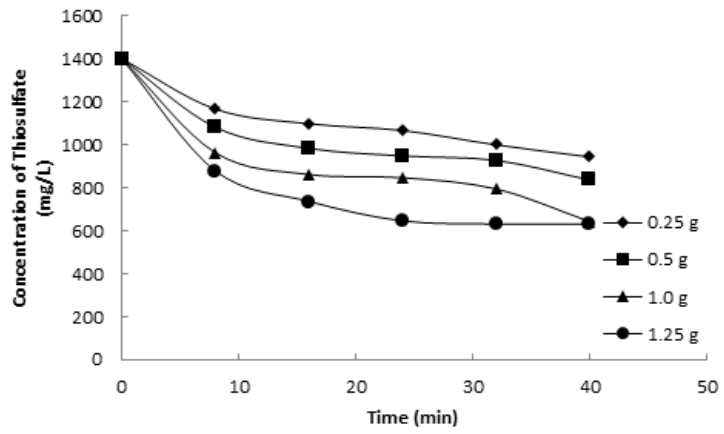

Fig. 6. Concentration of thiosulfate versus time for different catalyst amounts. $\mathrm{H}_{2} \mathrm{O}_{2}: 0.8 \mathrm{M}$, initial thiosulfate concentration $=1400 \mathrm{ppm}$.

\section{Effect of Temperature}

The temperature of the reaction is important to the efficiency of the reaction. Figures 7 and 8 describe the influence of temperature on the treatment process. With increase in temperature from $35^{\circ} \mathrm{C}$ to $45^{\circ} \mathrm{C}$ we found that the sulfate formation only shows an increment at the first three readings. After that it starts to decrease for the temperature of $35^{\circ} \mathrm{C}$, and remains constant for $45^{\circ} \mathrm{C}$. However, when the temperature is further increased to $55^{\circ} \mathrm{C}$, sulfate formation and/or thiosulfate drop is found to suppress. From these results it can be concluded that the optimum operating temperature for this $\mathrm{H}_{2} \mathrm{O}_{2}$ advanced oxidation process with $\mathrm{Al}_{2} \mathrm{O}_{3}$ catalyst is between $25^{\circ} \mathrm{C}$ and $45^{\circ} \mathrm{C}$.

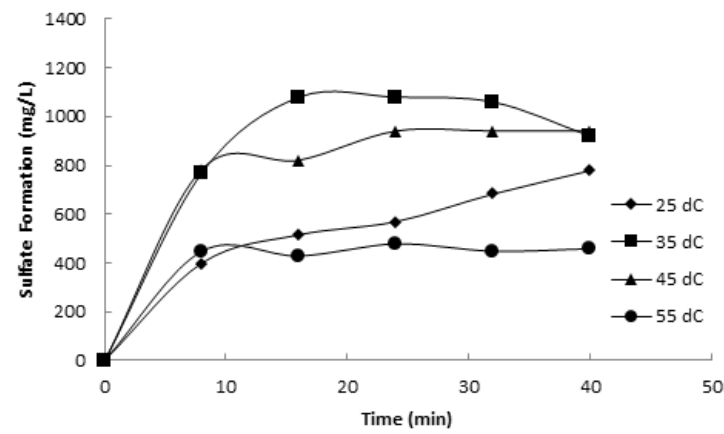

Fig. 7. Concentration of sulfate formation versus time in various temperatures. $\mathrm{H}_{2} \mathrm{O}_{2}: 0.8 \mathrm{M}$, initial thiosulfate concentration=1400ppm, Catalyst loading $=0.25 \mathrm{~g}$.

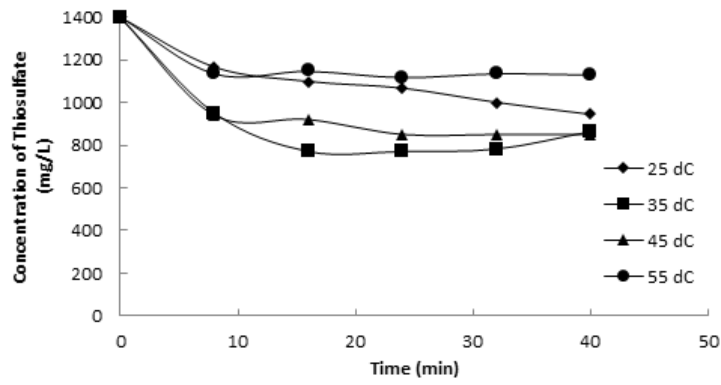

Fig. 8. Concentration of thiosulfate versus time in various temperatures. $\mathrm{H}_{2} \mathrm{O}_{2}: \quad 0.8 \mathrm{M}$, initial thiosulfate concentration $=1400 \mathrm{ppm}$, catalyst loading $=0.25 \mathrm{~g}$.

\section{E. Kinetic Study}

An empirical rate equation was developed. The orders with respect to all reactants and for the overall reaction were determined. The reactants were hydrogen peroxide $\left(\mathrm{H}_{2} \mathrm{O}_{2}\right)$ and thiosulfate ion $\left(\mathrm{S}_{2} \mathrm{O}_{3}{ }^{2-}\right)$. When a catalyst is used the reaction rate may be stated on a catalyst weight basis. Thus, the rate of the reaction becomes:

$$
\begin{aligned}
& \text { rate }=-k\left[\mathrm{~S}_{2} \mathrm{O}_{3}{ }^{2-}\right]^{\alpha}\left[\mathrm{H}_{2} \mathrm{O}_{2}\right]^{\beta}\left[\mathrm{Al}_{2} \mathrm{O}_{3}\right]^{\gamma} \\
& \mathrm{k}=\mathrm{Ae}^{(-\mathrm{E} / \mathrm{RT})}
\end{aligned}
$$

where $\mathrm{k}$ is the reaction rate constant and $\alpha, \beta$ and $\gamma$ are the reaction orders for $\mathrm{S}_{2} \mathrm{O}_{3}{ }^{2-}, \mathrm{H}_{2} \mathrm{O}_{2}$ and $\mathrm{Al}_{2} \mathrm{O}_{3}$ respectively. From (8)-(9), we can see that the rate is proportional with $\left[\mathrm{S}_{2} \mathrm{O}_{3}{ }^{2-}\right]^{\alpha}$, $\left[\mathrm{H}_{2} \mathrm{O}_{2}\right]^{\beta}$ and $\left[\mathrm{Al}_{2} \mathrm{O}_{3}\right]^{\gamma}$. The mathematical relations of this explanation are shown below, with rate $\alpha$ being $\left[\mathrm{S}_{2} \mathrm{O}_{3}{ }^{2-}\right]^{\alpha}$, rate $\beta$ being $\left[\mathrm{H}_{2} \mathrm{O}_{2}\right]^{\beta}$, and rate $\gamma$ being $\left[\mathrm{Al}_{2} \mathrm{O}_{3}\right]^{\gamma}$. Thus:

$$
\begin{aligned}
& \mathrm{r}_{\alpha}=\left[\mathrm{S}_{2} \mathrm{O}_{3}{ }^{2-}\right]^{\alpha} \\
& \ln _{\alpha}=\alpha \ln \left[\mathrm{S}_{2} \mathrm{O}_{3}{ }^{2-}\right] \\
& \mathrm{r}_{\beta}=\left[\mathrm{H}_{2} \mathrm{O}_{2}\right]^{\beta} \\
& \ln _{\beta}=\beta \ln \left[\mathrm{H}_{2} \mathrm{O}_{2}\right] \\
& \mathrm{r}_{\gamma}=\left[\mathrm{Al}_{2} \mathrm{O}_{3}\right]^{\gamma} \\
& \ln r_{\gamma}=\gamma \ln \left[\mathrm{Al}_{2} \mathrm{O}_{3}\right]
\end{aligned}
$$

Using the above equations, rates and orders with respect to each reactant are calculated. The orders of reaction with respect to thiosulfate, hydrogen peroxide and catalyst were found to be $0.421,0.556$ and 0.558 respectively. The order of reaction with 
respect to hydrogen peroxide was found by plotting the rate of reaction against concentration of hydrogen peroxide as shown in Figure 9 which is the logarithmic plot of the rate of the reaction of thiosulfate oxidation and hydrogen peroxide concentration. The slope of the plot gives us the order of reaction with respect to hydrogen peroxide. Using Arrhenius equation, activation energy was found to be $3507 \mathrm{kj} / \mathrm{mol}$.

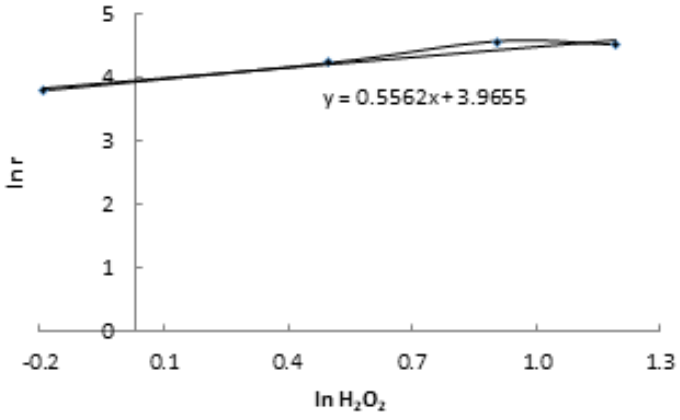

Fig. 9. Plot of the reaction order with respect to $\mathrm{H}_{2} \mathrm{O}_{2}$.

\section{CONCLUSION}

Thiosulfate from wastewater can be removed by catalytic oxidation using hydrogen peroxide as an oxidant. The following points can be concluded from this study:

- The reaction rate depends on the reactant species which are thiosulfate and $\mathrm{H}_{2} \mathrm{O}_{2}$ in this project. However, compared to thiosulfate, the concentration of hydrogen peroxide has a bigger effect on the reaction rate.

- The amount of catalyst also played an important role in supporting the rate of formation of sulfate ions. Increasing the amount of catalyst increases the rate of reaction.

- Temperature affects the treatment process. However, increase in temperature above $45^{\circ} \mathrm{C}$ has no positive effect on the progress of treatment process. The optimum temperature of the treatment process is in the range of $25^{\circ} \mathrm{C}$ to $45^{\circ} \mathrm{C}$.

- The treatment process is also affected by the dose of hydrogen peroxide. Dosage of higher hydrogen peroxide from a certain limit increases only the level of hydroxyl ions and has no fruitful effect on the treatment process. The optimum dosage of hydrogen peroxide in the current study was found to be $1.6 \mathrm{M}$.

- The rate of the reaction is also influenced by the initial thiosulfate concentration. Increase in the initial concentration of thiosulfate increases the rate of the reaction.

- The orders of reaction for all reactants were found positive, which means that increase in their initial concentration will increase the rate of the reaction.

\section{REFERENCES}

[1] R. H. Dinegar, R. H. Smellie, V. K. La Mer, "Kinetics of the acid decomposition of sodium thiosulfate in dilute solutions", Journal of the American Chemical Society, Vol. 73, pp. 2050-2054, 1951
[2] T. Yan, Removal of Cyanide, Sulfides and Thiosulfate from AmmoniaContaining Wastewater by Catalytic Oxidation, US Patent, No. 5360552, 2001

[3] DIONEX, Determination of Thiosulfate in Refinery and Other Wastewaters, Application Note 138, DIONEX, 2001

[4] D. C. Schreiber, S. G. Pavlostathis, "Biological oxidation of thiosulfate in mixed heterotrophic/autotrophic cultures", Water Research ,Vol. 32, No. 5, pp. 1363-1372, 1998

[5] N. Ahmad, S. Maitra, B. K. Dutta, F. Ahmad, "Remediation of sulfidic wastewater by catalytic oxidation with hydrogen peroxide", Journal of Environmental Sciences, Vol. 21, No. 12, pp. 1735-1740, 2009

[6] N. Ahmad, F. Ahmad, I. Khan, A. Daud Khan, "Studies on the Oxidative Removal of Sodium Thiosulfate from Aqueous Solution", Arabian Journal for Science and Engineering, Vol. 40, No. 2, pp. 289-293, 2015

[7] F. Ahmad, N. Ahmad, A. Z. Al-Khazaal, I. Alenezi, "Remediation of sulfidic wastewater by aeration in the presence of ultrasonic vibration", Engineering, Technology \& Applied Science Research, Vol. 8, No. 3, pp. 2919-2928, 2018

[8] F. Ahmad, "A new approach for the removal of thiosulfate from wastewater", International Journal of Chemical and Enviromental Engineering, Vol. 3, No. 5, pp. 303-308, 2012

[9] F. Ahmad, N. Ahmad, S. Maitra, "Treatment of Sulfidic Wastewater Using Iron Salts", Arabian Journal for Science and Engineering, Vol. 42, No. 4, pp. 1455-1462, 2017 